\title{
Application of Fuzzy Clustering in Agricultural Disaster Insurance
}

\author{
Ting Zhang \\ Economic Management Department, North China Electric Power University(NCEPU), Baoding, China \\ miyinting@gmail.com
}

\begin{abstract}
Facing frequent occurrences of natural disasters in recent years, the research and practice of natural disaster insurance should be paid more attention and intensified in our country,In order to reasonably determine the agricultural insurance rate and premium, we use the fuzzy clustering analysis method through effective quantization on the data of the known natural disasters. I think this will provide an effective basis for the formulation of insurance rate in different area as well as the different types of insurance in same area.
\end{abstract}

Keywords-fuzzy clustering; agricultural disaster; insurance premium rate

\section{INTRODUCTION}

Agricultural production heavily depends on the natural environment factors. Losses caused by natural disasters seriously restrict the development of agricultural production and the improvement of people's living standard, and make agriculture become a full risk fragile industry. While in the process of determining insurance scheme, the insurance rate largely determines the profit and loss of insured and the insurance company. Reasonable insurance rate should fully take account of the weather conditions and crop types in different regions, but each region for the development of unique insurance solutions are too cumbersome, so it's very necessary to usie both balanced approach to develop rates.

At present, some policy agricultural insurance in developed countries have a considerable scale,, Crop yield insurance formulate insurance contract according to the farm, crop varieties and different security level.

China's agricultural insurance pilot tried to be done in 1930s, but there was no insurance information records. A preliminary implementation appeared after the founding of new China. In the formal development of 1982 to early 2004,our country basically trail in the framework of the commercial insurance. In 2004 the Central Document No. 1 proposed a national strategic policy on developing policy agricultural insurance and subsidies for agricultural insurance to speed up the pace of agricultural insurance, All regions have started agricultural insurance pilot. Basic insurance rates and premiums based on experience and consultation. In 2004 the Central Document No. 1 proposed a national strategic policy on developing policy agricultural insurance and subsidies for agricultural insurance to speed up the pace of agricultural insurance, All regions have started agricultural insurance pilot. Basic insurance rates and premiums based on experience and consultation.

This study use the fuzzy clustering analysis method from the actual situation of Chinese agricultural management and statistical date of calculation. This will provide technical support for the healthy development of Chinese agricultural insurance

\section{THE PRINCIPLE OF FUZZY ClUSTER}

Fuzzy clustering analysis of clustering is one of the methods of fuzzy mathematics, which develop Cluster analysis in accordance with certain requirements and rules on the things you want to study. And it's a scientific and effective multivariate statistical method to study the "Like attracts like.". This method determines the hydrodynamic relation among samples through mathematical quantitative methods, so as to draw an objective classification type.

The general practice of clustering analysis is: Select statistical data; standardize data; establish fuzzy similar matrix; solve fuzzy equivalence matrix; cluster analysis.

\section{EXAMPLES OF THE APPLICATION OF FUZZY CLUSTERING}

\section{A. Integrated analysis of meteorological data}

First, meta-analysis the meteorological data of the province $\mathrm{P}$ during 2002-2011, draw the corresponding flood disaster occurs, area floods, high winds, hail occurrence, and thus come to disaster expected loss rate.

Table 1 SiX Winds Above The Disaster Areas (Times) Statistics

\begin{tabular}{|l|l|l|l|l|l|l|l|l|l|l|}
\hline Area & $\mathbf{A}$ & $\mathbf{B}$ & $\mathbf{C}$ & $\underline{\mathbf{E}}$ & $\underline{\mathbf{F}}$ & $\underline{\mathbf{F}}$ & $\underline{\mathbf{G}}$ & $\underline{\mathbf{H}}$ & $\mathbf{I}$ & $\underline{\mathbf{J}}$ \\
\hline $\begin{array}{l}\text { Total } \\
\text { wind }\end{array}$ & $\underline{46}$ & $\underline{41}$ & $\underline{80}$ & $\underline{0}$ & $\underline{2}$ & $\underline{30}$ & $\underline{25}$ & $\underline{12}$ & $\underline{0}$ & $\underline{2}$ \\
\hline
\end{tabular}

TABle 2 The Situation Of HAIl DisAster REgIONS (TIMES) Statistics

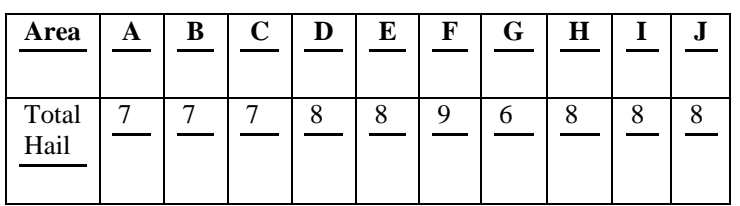

\section{B. Fuzzy clustering analysis}

Take universe as $X=\{A, B, C, D, E, F, G, H, I, J\}$ in ten regions. Each area is composed of four indicators, respectively, times of the wind more than six times within a decade, hail times within a decade, annual average loss rate, mean years of $\mathrm{Z}$ values. The raw data is as follows: 




The standard deviation of the original data standardization

$$
\mathrm{x}_{\mathrm{ij}}^{\prime}=\frac{x_{i j-} x_{i}}{s_{i}}(1 \leq j \leq m)
$$

Among

them

$$
\mathrm{x}_{i}=\frac{1}{m} \sum_{j=1}^{m} x_{i j}, \quad \mathrm{~s}_{i}=\sqrt{\frac{1}{m-1} \sum_{j=1}^{m}\left(x_{i j}-\overline{x_{i}}\right)^{2}},
$$

Specifications matrix is obtained:

$$
\left[\begin{array}{llll}
-0.1389 & -0.9037 & -1.0394 & -1.0410 \\
-0.1537 & -0.8926 & -1.0431 & -1.0447 \\
-0.0837 & -0.9436 & -1.0249 & -1.0259 \\
-1.0027 & -0.0082 & -0.9955 & -1.0018 \\
-0.8488 & -0.2167 & -1.0537 & -1.0594 \\
-0.2475 & -0.8201 & -1.0634 & -1.0655 \\
-0.2064 & -0.8529 & -1.0548 & -1.0570 \\
-0.4386 & -0.6536 & -1.0882 & -1.0922 \\
-1.0028 & -00086 & -0.9943 & -1.0028 \\
-0.8492 & -02175 & -10529 & -1.0597
\end{array}\right]
$$

Use the cosine formula $\mathrm{r}_{i j}=\frac{\sum_{k=1}^{m} x_{i k} \cdot x_{j k}}{\sqrt{\sum_{k=1}^{m} x_{i k}^{2}} \cdot \sqrt{\sum_{k=1}^{m} x_{j k}^{2}}}$

For the fuzzy similar matrix, to: $\mathrm{R}$

Take $\lambda=0.8$, get the classification matrix:Y

$\mathrm{Y}=\left[\begin{array}{llllllllll}1 & 1 & 1 & 0 & 1 & 1 & 1 & 1 & 0 & 1 \\ 1 & 1 & 1 & 0 & 1 & 1 & 1 & 1 & 0 & 1 \\ 1 & 1 & 1 & 0 & 1 & 1 & 1 & 1 & 0 & 1 \\ 0 & 0 & 0 & 1 & 1 & 0 & 0 & 1 & 1 & 1 \\ 1 & 1 & 1 & 1 & 1 & 1 & 1 & 1 & 1 & 1 \\ 1 & 1 & 1 & 0 & 1 & 1 & 1 & 1 & 0 & 1 \\ 1 & 1 & 1 & 0 & 1 & 1 & 1 & 1 & 0 & 1 \\ 1 & 1 & 1 & 1 & 1 & 1 & 1 & 1 & 1 & 1 \\ 0 & 0 & 0 & 1 & 1 & 0 & 0 & 1 & 1 & 1 \\ 1 & 1 & 1 & 1 & 1 & 1 & 1 & 1 & 1 & 1\end{array}\right]$

\section{Classification:}

Region 1 [PA, PB, PC, PF, PG]

Region 2 [PE, PH], PJ

Region 3 [PD, PI]

Calculate the disaster expected loss rate three species a.b.c of three regional

The results are as follows:

Region 1: a,b,c were 6.88\%, 5.35\%, 5.53\% respectively

Region 1: a,b,c were $7.10 \%, 5.53 \%, 5.71 \%$ respectively

Region 1: a,b,c were 5.55\%, 4.26\%, 4.00\% respectively

\section{Decide the insurance rate according to the region}

The calculation formula for making pure rate $\mathrm{F}^{\prime \prime}$

$$
F^{\prime \prime}=S_{m} \times(1+\Phi) \times \varphi
$$

Type $\mathrm{m} \mathrm{S}$ can be used as basic indicators developed pure rate. For the stability coefficient, the extent of discrete loss rate, also known as the coefficient of variation, can be used as an auxiliary index for pure rate. Calculated by the expression stability coefficient can be:

$$
\begin{gathered}
\Phi=\frac{\sigma}{S_{m}} \times 100 \% \\
\sigma=\frac{1}{n-1} \sum_{\mathrm{i}=1}^{n}\left(S_{\sigma i}-S_{m}\right)
\end{gathered}
$$

Three regions corresponding to the pure rate of crop Region 1: a,b,c were $7.13 \%, 5.57 \%, 5.79 \%$ respectively Region 1: a,b,c were $7.37 \%, 5.75 \%, 5.98 \%$ respectively

Region 1: a,b,c were $5.66 \%, 4.34 \%, 4.07 \%$ respectively

Here the regional insurance premium calculation is determined by:

The insurance premium rate $\mathrm{F}=$ Pure rate + administrative cost rate

The results of the insurance premium rate are as follows:

Region 1: a,b,c were $8.56 \%, 6.68 \%, 6.95 \%$ respectively

Region 1: a,b,c were $8.84 \%, 6.90 \%, 7.17 \%$ respectively

Region 1: a,b,c were $6.79 \%, 5.20 \%, 4.88 \%$ respectively

\section{COUNTERMEASURE}

Based on the classification results and combined with the original data, we can find that, disaster losses of crop area 1 is significantly higher than the region 2 and region 3 . According on the corresponding losses in different regions to develop the corresponding insurance premium rate, increase the feasibility of insurance scheme, to avoid the "make it rigidly uniform" type insurance rate situation caused heavy disaster area -- insurance rate is too low, the insured waiver insured; light disaster area insurance rates are too high, the insurance company underwriting losses, give up. The insured and the insurance company's interests, promote the long-term development of agricultural disasters insurance.

\section{REFERENCES}

[1] DengXH, BarnettJB, Vedenov VB. Is there aviable market for area 2 based cropinsurance?[J].Ame rJAg rEcon,2007,89(2):5082519

[2] .HartE C, Haye sJD ,Babcock AB.Insuring eggs in baskets: should the government insure individual risks? [J]. Canadian Journal of Agricultural Econom2 ics ,2006 54:1212137

[3] ChenSL, Miranda JM.Modeling Texasdry landcot 2 tonyields, with application to crop in surance actuari 2 alrating [J]. Journal of Agricultural and Applied E2conomics ,2008,40(1):2392252

[4] Goodwin KB ,KerPA .Non paramet rice stimation of crop yield distributions :Implications for rating group 2 risk crop Insurance contracts [J].American Journal of Agricultural Economics ,1998, 80(1):1392153 